\title{
Working from 9 to 6? An analysis of in-home and out-of-home working schedules
}

\author{
Bayarma Alexander • Martin Dijst • Dick Ettema
}

Published online: 10 January 2010

(C) The Author(s) 2010. This article is published with open access at Springerlink.com

\begin{abstract}
The widespread adoption of information and communication technologies (ICT) and flexible work arrangements have enabled people to schedule their work activities in more flexible ways. New forms of working have already emerged. However, research about flexible work schedules is still scarce. The aim of this study is to determine the factors impacting the propensity to adopt a flexible work schedule, and establish how and to what extent the timing of work is influenced by ICTs, work, and sociodemographic characteristics. The analysis suggests that work-related characteristics and ICT usage seem to be more important for work-schedule flexibility than sociodemographic characteristics are.
\end{abstract}

Keywords Work activity - Working schedule - Start and end time · ICT · The Netherlands

\section{Introduction}

Work is an activity with a crucial role in shaping overall activity-travel patterns. Past studies have suggested that the work activity serves as a peg around which other activities are scheduled (Cullen and Godson 1975; Jones et al. 1983; Kitamura 1983; Schwanen and Dijst 2003). In addition, Hägerstrand (1970) and other researchers argue that activities that are fixed in space and time, such as work, determine the opportunities to conduct other flexible activities. Using the space-time fixity concept (which represents the degree of space-time fixity of daily activities), Schwanen and Kwan (2008) found that work tends to be the most binding activity in space and time.

However, recent studies suggest that, with the widespread adoption of information and communication technologies (ICTs) together with an increase in the flexibility of work arrangements, people now schedule their work activities in a more flexible way (Handy and

B. Alexander $(\bowtie) \cdot$ M. Dijst $\cdot$ D. Ettema

Urban and Regional Research Centre Utrecht (URU), Faculty of Geographical Sciences, Utrecht

University, P.O. Box 80115, 3508 TC Utrecht, The Netherlands

e-mail: b.alexandr@geo.uu.nl 
Mokhtarian 1996; Mokhtarian and Salomon 1997; Kwan 2002; Couclelis 2003; Graaff and Rietveld 2007; Schwanen and Kwan 2008). New forms of working with less conventional temporal schedules have already emerged (Pendyala et al. 1991; Mannering and Mokhtarian 1995; Vilhelmson and Thulin 2001; Lyons and Haddad 2008). Increasingly, urban and transport planners are interested in the impacts of this growing flexibility of working while travelling, because of its potential contribution to the reduction of peak period congestion (Lund and Mokhtarian 1994; Mokhtarian 1998) and the improvement of air quality.

Most of the early studies in this area concentrated on the effects of telecommuting on travel demand (Pendyala et al. 1991; Mannering and Mokhtarian 1995; Koenig et al. 1996; Vilhelmson and Thulin 2001), although recently more attention has been directed toward work-hour arrangements (Yeraguntla and Bhat 2005; Vana et al. 2008) and different forms of working practice, for instance, part-day homeworking (combining working at home with working at the work place, Lyons and Haddad 2008). The studies have been primarily concerned with the frequency of homeworking as a function of sociodemographics, job related characteristics, and travel-behaviour variables. For instance, Pendyala et al. (1991) and Koenig et al. (1996) found a significant reduction in the amount of work-related travel (the total distance travelled by telecommuters). Lyons and Haddad (2008) observed that there has been an increasing incidence of part-day homeworking, which can displace the timing of a commute trip. Although many studies have addressed the impact that ICT has on commuting behaviour as a result of telecommuting, the relationship between ICT use and the flexibility of work has received much less attention. Nevertheless, this relationship is of interest for a couple of reasons. First, ICT may allow work to be organized so that work activities are less strictly bound to specific times and to the work place. More flexibility in work time would ensue and consequently might allow firms to offer jobs with flexible work hours and workers to accept these jobs. Potentially, the timing of work trips may shift, thereby impacting on traffic patterns and congestion. However, the extent to which the flexibility of work times leads to actual changes in the timing of work may be limited. Whereas for a long time work has served as a structuring element for the timing of other activities, with increased flexibility the timing of work becomes structured by constraints set by other activities, such as household or social obligations that take place at more or less fixed times. Thus, even though work may become fully flexible from a functional perspective, the earliest start and end times individuals would consider for working are bounded. To understand the impact of ICT on work scheduling, we need to find these boundaries. They could well be different for different work arrangements, such as working in the office or working from home.

The aim of this study is therefore twofold. First, to gain insight into the impact of ICTs on offering and accepting flexible work schedules, we have explored the impact of ICT along with sociodemographic and work-related factors on the propensity to have a flexible work schedule. Second, we have examined how and to what extent the actual timing of work and the boundaries of acceptable start and end times are influenced by ICTs, workrelated and sociodemographic characteristics. Aspects of ICT considered here include the ownership of ICT, the purpose of ownership, and the actual use. We concentrate on workdays, because the scheduling of work activities on workdays is different from that on non-workdays (Schwanen and Dijst 2003; Sall et al. 2005).

To investigate the propensity of having flexible work hours, a binary logit model was estimated. Stochastic frontier models were applied to estimate the earliest possible start and the latest possible end times of work activities, based on the observed start and end times of work activities at home and the workplace. While survey data tell us when work 
actually starts and ends, they do not provide any information about when people would be willing to start and finish their work. Thus the earliest possible start and the latest possible end time are treated as unobserved boundaries that influence the actual start and end times of work. Based on past studies (Damm 1983; Bhat and Singh 2000; Schwanen and Dijst 2003; Koenig et al. 1996), we distinguish four categories of working arrangement: (a) in-home working, which represents whole-day homeworking without commuting; (b) out-of-home working, which represents working at a conventional work location or other location(s) outside the home on any given day; (c) before-commute working, which refers to working at home at the beginning of the day until commuting; (d) after-commute working, which refers to working at home at the end of the day after out-of-home work.

The rest of the paper is organized as follows. In the next section, we present the study's background. In the following section, we discuss the data employed and the methodology. This section is followed by the empirical results. In the final section we put forward our conclusions.

\section{Study background}

Space-time constraints and flexible work schedules

It has long been recognized that an individual's activity behaviour is governed by a set of constraints: capability, coupling, and authority (Hägerstrand 1970). Collectively, these constraints determine the level of the space-time flexibility of activitiesthat is to say, the degree to which the timing, duration or location where they are undertaken can be chosen freely (Kwan 2000). Capability constraints refer to biological, instrumental, and physical limitations (for example, sleep, personal care). Physiological needs may prevent a worker working between 3 a.m. and 6 a.m. Another example of a capability constraint is the maximum travel speed of individuals using a certain transport mode. Coupling constraints specify the requirements of where, when, and for how long people associate themselves with others and with materials or tools. For example, working mothers may opt to work only during school hours, allowing them to pick up their children. Authority constraints represent the capacity of activity places, rules, and laws. Burns (1979) foresaw that a flexible work schedule might help people overcome these constraints. He argues that, as the working schedule becomes more flexible, the level of space-time autonomy increases and the daily activity prisms also change in position and size. For instance, the flexible start and end times of work enable people to enjoy more space-time autonomy and visit locations at times that were not previously possible. However, the need to profit from increasing work flexibility may differ between individuals, depending on work, sociodemographic, and ICT-related factors. The remainder of this section includes an overview of the potential impacts of these factors on adopting and using flexible work arrangements.

Determinants of having a flexible schedule

\section{Work-related characteristics}

Several studies indicate that the number of workers with a flexible schedule that permits variation in the start time of work has increased (e.g. Sall et al. 2005). While alternative schedules are becoming more frequent, they are still more common in some industries and occupations than others (Tausig and Fenwisk 2004). For example, Vana et al. (2008) found 
that employees in managerial, technical/professional, and clerical occupations are more likely to take up conventional work-hour arrangements. Job-related factors have accounted more than demographic and family demands for the distribution of flexible time among most employees (Swanberg et al. 2005). Furthermore, Golden (2001) found that the number of usual weekly hours had two salient associations with access to flexible schedules. The greatest advantage in gaining flexibility in start and end times of work seems to belong to those with a part-time job status and those who work for more than $50 \mathrm{~h}$ per week. Individuals starting work earlier than 9 a.m. have less working schedule flexibility than employees who start work later (Yeraguntla and Bhat 2005). Venkatesh and Vitalari (1992) have analysed the performance of supplemental work at home. On the personal level, results indicate that the amount of time spent on supplemental work is positively related to the work's self-determination variables (flexibility) and the portability of the work task. Furthermore, the changes in organizational demands have led to the rise of the 'post-modern' professional (Kakihara 2005; Kakihara and Sørensen 2004). The most skilled or highly educated employees can successfully access flexible working schedules and arrange flexible working arrangements through their position or leverage (Hamermesh 1996).

\section{ICT characteristics}

The diversification of flexible work forms is often linked with the diffusion of new information and communication applications and services. There is interaction between technological innovation and organizational change. Mokhtarian et al. (2005) argues that the advances in information and communication technologies over the past decade may have changed some of today's employees' preferences and attributes. However, the adoption of telecommuting, in general, is still taking place more slowly than its strongest proponents expected, perhaps owing to the persistence of various attributes and constraints. ICT supports and fosters the implementation of flexible work forms and increases their efficiency (Valenduc and Vendramin 2001). Couclelis (2004) asserted that, equipped with laptop computers and portable phones, certain work activities could take place in many places and times, all in one period, or alternative times (sometimes before, sometimes after some other activities), or in some regular time sequence interwoven with other activities, or several different times, or at any arbitrary time the individual may choose. Activities that could have been carried out online are believed to be less fixed in space and time and those aided by the internet are more flexible in time (Schwanen and Kwan 2008). Venkatesh and Vitalari (1992) examined the role of information technologies in the performance of supplemental work at home (for instance, distributed work arrangements where the home is used as a setting for job-related work by individuals employed fulltime outside, after normal work hours or on a weekend). Their results show that the amount of time spent on supplemental work is positively related to the availability of telecommunication links between the firm and the home.

\section{Sociodemographic characteristics}

Fast and Frederick (1996) found that flex-time (involving variation in work start time) reduced perceived time stress (time demands at work interfering with time spent with family and friends). If employees can determine their own working hours, they can decide to start early and have more time at the end of the day for non-work activities. Using datasets from Columbus (Ohio, USA) and Utrecht (The Netherlands), Schwanen and Kwan (2008) found gender differences in the temporal constraints of work activity. Men living 
with a partner and mothers with pre-school children have more access to flexible work schedules (Golden 2001). Moreover, several studies indicate that women opt for flexible work arrangements for better childcare arrangements, whereas men use these arrangements for other job-related reasons (Hinze 2000; Presser 2003). Spitze (1988) found that the need to have at least one partner available for domestic chores and caregiving is more easily realized if work schedules are flexible. An increase in flexible work practice becomes important in enabling work and caring responsibilities to be reconciled (Kwan 2002; Venkatesh and Vitalari; 1992).

Besides these employment characteristics, personal and household and residential-area attributes may also affect the timing of work activities. For example, Yeraguntla and Bhat (2005) found that highly urbanized and CBD residents tend to have greater work-schedule flexibility than residents of suburban and other areas do.

Overall, it can be concluded from the considerable literature in this area that the decision to opt for a flexible work schedule and decisions about actual and acceptable work times are both influenced by work-related and sociodemographic factors. However, the impact of ICT on the flexibility of work schedules and work timing has received much less investigation. The aim of this study is to investigate these impacts, while accounting for work-related and sociodemographic factors.

\section{Research design and methodology}

Data source and sample characteristics

The data for the present study was gathered through a survey collected in the UtrechtAmersfoort-Hilversum region in 2007. The dataset consists of an activity-travel-communication diary completed for 2 days and was conducted among single and dual-worker households. The neighbourhoods in the research area were selected based on a combined income, density, and accessibility matrix (4 incomes, 5 densities, and 3 train-accessibility classes). In total 662 respondents completed the questionnaire, either online or in a mail out/mail back paper-and-pencil format. The respondents were asked to report the details about start/end times and locations (office, home) of their work and other activities. They were also asked to indicate how often they used different types of ICT device (landline and mobile phones, PDAs, laptop computer with internet) for work and/or private purposes and their motivations for ICT usage and ownership. Further information about the data is available in Hubers et al. (2008) and Tillema et al. (2008) .

We chose this dataset, because it allows us to investigate the factors affecting the choice to work in a flexible work schedule and the timing of paid-work activities at home, out-ofhome, and before/after commute. The original dataset was screened for empirical analysis, selecting only observations (diary days) on which respondents had worked. The final sample for analysis included 830 person-days from 542 respondents who were engaged in in-home and out-of-home work activities during the survey days.

Some key characteristics of the sample are given in Table 1 . More than $50 \%$ of the respondents work from home at least 1 day per week. This suggests that flexible work schedules are rather common amongst this sample. The mean value of working hours was $32.6 \mathrm{~h}$ per week. The occupation distribution shows that the sample slightly overrepresented high-level professionals: $45 \%$ of the respondents were highly educated professionals (scientific, technical, healthcare, ICT, and so forth). The car was the main commute mode for most respondents (36\%). The average commute distance was $11.6 \mathrm{~km}$. 
Table 1 Frequency distribution of variables

\begin{tabular}{|c|c|c|c|c|}
\hline Variables & $N$ & $\%$ & Mean & SD \\
\hline \multicolumn{5}{|l|}{ Work related attributes } \\
\hline Working from home & 419 & & & \\
\hline Yes & & 54.0 & & \\
\hline Sometimes & & 28.5 & & \\
\hline Never & & 17.6 & & \\
\hline Weekly working hours & 542 & & 32.6 & 12.1 \\
\hline Occupation & 542 & & & \\
\hline Manager & & 7 & & \\
\hline High professional & & 45 & & \\
\hline Low professional & & 26 & & \\
\hline Clerical & & 11 & & \\
\hline Service worker & & 5 & & \\
\hline Low skilled jobs & & 6 & & \\
\hline Commute mode & 475 & & & \\
\hline Public transport & & 19.4 & & \\
\hline Car & & 44.6 & & \\
\hline Other (walking and cycling) & & 36.0 & & \\
\hline Frequency of train use per week & 542 & & 1.78 & 3.60 \\
\hline Commute distance $(\mathrm{km})$ & 542 & & 11.6 & 15.98 \\
\hline \multicolumn{5}{|l|}{ ICT characteristics } \\
\hline Frequency of mobile calls & 540 & & & \\
\hline More than 5 calls a day & & 16.7 & & \\
\hline 2-5 Calls a day & & 27.6 & & \\
\hline 1 Call a day & & 12.1 & & \\
\hline Couple of days per week & & 17.4 & & \\
\hline $1 \times$ Per week & & 7.60 & & \\
\hline 1 Or a couple of times per month & & 8.50 & & \\
\hline (Almost) never & & 10.1 & & \\
\hline Internet experience (years) & 542 & & 7.89 & 4.54 \\
\hline Duration of private calls (min) & 542 & & 24.8 & 28.3 \\
\hline Buy laptop enable working anywhere, anytime & 541 & 9.40 & & \\
\hline $\begin{array}{l}\text { Regularly making work related calls/send } \\
\text { email outside working hours }\end{array}$ & 541 & 43.6 & & \\
\hline Combined phone/internet package & 542 & 53.7 & & \\
\hline $\begin{array}{l}\text { Receive (partial) reimbursement of expenses } \\
\text { for mobile phone cost from employer }\end{array}$ & 542 & 12.5 & & \\
\hline \multicolumn{5}{|l|}{ Personal and Household characteristics } \\
\hline Male & 542 & 48 & & \\
\hline Age (years) & 542 & & 45.6 & 10.7 \\
\hline Household composition & 542 & & & \\
\hline Single & & 21 & & \\
\hline Living with a partner only & & 46 & & \\
\hline Living with a partner and have children & & 33 & & \\
\hline
\end{tabular}


Table 1 continued

\begin{tabular}{|c|c|c|c|c|}
\hline Variables & $N$ & $\%$ & Mean & SD \\
\hline Net household income per month & 542 & & & \\
\hline Low $(2,000$ euro or less $)$ & & 20 & & \\
\hline High (more than 3,000 euro) & & 44.2 & & \\
\hline Urbanization degree & 542 & & & \\
\hline Less $\left(<1,000\right.$ address $\left./ \mathrm{km}^{2}\right)$ & & 19.9 & & \\
\hline Partner's working hour & 327 & & 20 & \\
\hline Presence of children at home & & 35.6 & & \\
\hline
\end{tabular}

With respect to the frequency of mobile calls, $16.7 \%$ of the respondents made more than five calls a day, while about $28 \%$ had a frequency of between 2 and 5 . The average number of years of internet experience was 7.9. Only $9.4 \%$ of the respondents bought a laptop with the purpose of being able to work anywhere, anytime. As shown in Table 1, more than $40 \%$ of the sample regularly made work-related calls and sent emails outside working hours. The majority of the sample $(53.7 \%)$ had a combined phone and internet package. The share of men in the sample was $48 \%$.

Defining the flexible work schedules

Flexible work schedules have been extensively researched in social, labour economics, and transportation studies (Toffler 1980; Chesley 2005; Golden 2001; Yeraguntla and Bhat 2005). Each field employs its own specific definition of flexible schedules for work. In social science, for instance, the flexible work schedule refers to a family-friendly schedule that allows people to reconcile their work and domestic responsibilities (Toffler 1980; Chesley 2005). In labour economics studies, the flexible work schedule includes reduced hours and/or work-days, telecommuting or non-standard start and stop times (Sullivan and Lussier 1995). Researchers in the activity-based analysis of travel behaviour, for example Yeraguntla and Bhat (2005), define flexibility as: the ease with which an employee can arrive 30-45 min late at work.

The above multidisciplinary review indicates that there is a lack of consensus over the definition of a flexible working schedule. In the current study, we define flexibility in the work schedule as: an employee's ability to choose when to start and end work on a given day. In the survey, the question regarding flexibility ran as follows: "To what extent are you able to choose your own start and end times for work?" A total of 419 individuals filled out this question, therefore the sample size was reduced from 542 to $419: 26.5 \%$, totally flexible; $52.4 \%$, partially flexible; $21.1 \%$, totally inflexible. The first two groups were put together in the flexible category and the last group became the inflexible category.

Independent variables

Three types of variable are available for the analysis: work-related, ICT and personalhousehold attributes. The choice of the independent related variables was guided by the previous studies reviewed in "Study background". With regard to the ICT variables, the respondents were asked to report what kind of information and communication devices (laptop, desktop computer, mobile/landline phone, personal digital assistant, and so forth) they possessed and how often they used them for work and private purposes. Our data 
indicate that the majority of the sample possesses a personal computer at home. It does not differentiate our sample. Therefore we used the use of laptop computer for the analysis. In this article we have used the financial aspect of mobile phone use as ICT variable. For example: those financially reimbursed for mobile phone use by their employer seem to use it more for work-related phone calls. On the other hand, it shows that the work organization supports their workers to use ICTs more in order to effectuate working from home and other places. Finally, nowadays many people use combined ICT services (phone with internet) because it provides inexpensive and unlimited access to the Internet. Therefore it would be interesting to examine how such attractive offer affect the flexibility of work schedule. Furthermore, we expect that those using such combined ICT services are more likely to be highly educated people and able to arrange their work schedule independently in more flexible way.

\section{Methodology}

As indicated in "Introduction", two models were applied in this study: binary logistic regression and stochastic frontier models.

\section{Binary logistic regression}

A binary logistic regression analysis was carried out to identify the factors that most affect the propensity to have a flexible work schedule. The dependent variable of the logistic regression is as described in the previous section. We coded flexibility as 1 and inflexibility as 0 . In total, the effects of 21 explanatory variables were tested. A positive sign means that the explanatory variable helps increase the probability of having a flexible work schedule and a negative sign implies the opposite effect. The results are presented in Table 2 (only significant effects are included) and discussed in the next section. An iterative maximumlikelihood procedure was used as the method of estimation.

\section{Stochastic frontier model}

As reported in the first section, stochastic frontier models were applied to estimate the earliest possible start time (EPST) and the latest possible end time (LPET) of work. We chose this modelling framework because stochastic frontier modelling is the most suitable and is often adopted in econometric and transportation studies to model unobserved boundary conditions (Aigner et al. 1977; Kitamura et al. 2000; Nehra et al. 2004).

In the context of this study, the observed start and end times of work are used as the dependent variables of stochastic frontier models.

$$
T_{0}=\tau_{0}+u_{0} \text { and } T_{t}=\tau_{t}-u_{t}
$$

where $T_{0}$ and $T_{t}$ are the observed start and end times of work; $u_{0}$ and $u_{t}$ are nonnegative random variables; $\tau_{0}$ and $\tau_{t}$ are unobserved frontiers for $T_{0}$ and $T_{t}$. The stochastic frontier model can be applied to these relationships as follows:

$$
T_{i}=\beta^{\prime} X_{i}+\varepsilon_{i}=\beta^{\prime} X_{i}+v_{i}+u_{i}
$$

where $i$ is the observation, $T_{i}$ is the observed start time of work, $\beta$ is the vector of coefficients, $X_{i}$ is the vector of explanatory variables, and $\varepsilon_{i}$ is error term, whereby $\varepsilon_{i}=v_{i}+u_{i}$ with $-\infty<v_{i}<\infty$ and $u_{i}>0$. 
Table 2 Binary Logistic Regression results for flexible work schedule

\begin{tabular}{|c|c|c|c|c|}
\hline Explanatory variable & Coef & $\mathrm{SE}$ & Wald $\left(\chi^{2}\right)$ & $\overline{\operatorname{Exp}(B)}$ \\
\hline \multicolumn{5}{|l|}{ Work-characteristics } \\
\hline \multicolumn{5}{|l|}{ Occupation } \\
\hline \multicolumn{5}{|l|}{ Manager } \\
\hline High professional & 1.15 & 0.34 & 11.3 & 3.15 \\
\hline \multicolumn{5}{|l|}{ Low professional } \\
\hline \multicolumn{5}{|l|}{ Clerical } \\
\hline \multicolumn{5}{|l|}{ Service worker } \\
\hline \multicolumn{5}{|l|}{ Low skilled jobs } \\
\hline $\begin{array}{l}\text { Recently increased the number of working } \\
\text { hours }\end{array}$ & -1.51 & 0.62 & 5.89 & 0.22 \\
\hline Frequency of train use & 0.27 & 0.09 & 7.41 & 1.04 \\
\hline \multicolumn{5}{|l|}{ ICT characteristics } \\
\hline $\begin{array}{l}\text { Regularly making work related calls/send } \\
\text { email outside working hours }\end{array}$ & 1.02 & 0.37 & 7.64 & 2.77 \\
\hline Combined phone/internet package & -0.87 & 0.31 & 7.91 & 0.42 \\
\hline $\begin{array}{l}\text { Receive (partial) reimbursement of expenses } \\
\text { for mobile phone cost from employer }\end{array}$ & 1.26 & 0.76 & 2.21 & 3.05 \\
\hline \multicolumn{5}{|l|}{ Personal and Household characteristics } \\
\hline Age (years) & 0.04 & 0.01 & 8.1 & 1.04 \\
\hline \multicolumn{5}{|l|}{ Net household income per month } \\
\hline Low $(2,000$ euro or less $)$ & -0.64 & 0.43 & 2.31 & 0.53 \\
\hline High (more than 3,000 euro) & 1.12 & 0.51 & 4.71 & 3.08 \\
\hline$N$ observation & 419 & & & \\
\hline$-2(L)$ & 318.5 & & & \\
\hline$R^{2}$ & 0.20 & & & \\
\hline $\mathrm{PCP}$ & 96.4 & & & \\
\hline
\end{tabular}

Coefficients are statistically significant for $p<0.05$

$S E$ standard error, $P C P$ percentage correctly predicted

In the current study, $\beta^{\prime} X_{i}+v_{i}$ can be viewed as the location of the EPST with the random element $v_{i}$. The observed start time of work will not exceed $\beta^{\prime} X_{i}+v_{i}$ because $u_{i}$ is nonnegative. The location of the LPET can be defined in similar way:

$$
T_{i}=\beta^{\prime} X_{i}+\varepsilon_{i}=\beta^{\prime} X_{i}+v_{i}-u_{i}
$$

Typically, $v_{i}$ is assumed to be normally distributed and a truncated (half) normal distribution is used for $u_{i}$. The distribution of $\varepsilon_{i}$ in the stochastic frontier model has been described by Aigner et al. (1977):

In the cost frontier model $: h(\varepsilon)=\frac{2}{\sqrt{2 \pi \sigma}}[1-\Phi(\varepsilon \lambda / \sigma)] \exp \left(-\frac{\varepsilon^{2}}{2 \sigma^{2}}\right) ; \quad-\infty<\varepsilon<\infty$ 
In the production frontier model $: h(\varepsilon)=\frac{2}{\sqrt{2 \pi \sigma}}[\Phi(\varepsilon \lambda / \sigma)] \exp \left(-\frac{\varepsilon^{2}}{2 \sigma^{2}}\right) ; \quad-\infty<\varepsilon<\infty$

where $\sigma^{2}=\sigma_{u}^{2}+\sigma_{v}^{2} ; \lambda=\sigma_{u} / \sigma_{v} ; v \sim N\left(0, \sigma_{v}^{2}\right)$ and $u$ has the following density function:

$$
g(u)=\frac{2}{\sqrt{2 \pi \sigma_{u}}} \exp \left[-\frac{u^{2}}{2 \sigma_{u}^{2}}\right] ; \quad u \geq 0
$$

It is hypothesised in this study that $\beta^{\prime} X_{i}+v_{i}$ represents the earliest possible start time or the latest possible end time of working out-of-home and in-home. In this study, all models assume that $u_{i}$ has an exponential distribution. Thus, its expected value and variance are evaluated respectively as:

$$
E\left(u_{i}\right)=\hat{\sigma}_{u} \text { and } \operatorname{var}\left(u_{i}\right)=\hat{\sigma}_{u}^{2}
$$

In this paper, the following stochastic frontier models are presented:

- The models of the earliest possible start time for working out-of-home; in-home, and before commute. The observed start times for all types of working form are used as a dependent variable. The definitions of the work forms were presented in the first section.

- The models of the latest-possible-end-time model for working out-of-home; in-home working, and after commute. The dependent variable of the LPST models is the observed end time for working.

\section{Results}

Binary logistic regression results

Table 2 contains the estimation results for the binary logistic regression model. Although many variables were tested, only those that were significant have been retained and presented here. The estimation results of the binary logistic regression suggest that, in terms of the work-related variables, being a high-level professional increases the probability of having a flexible work schedule compare to the low skilled workers. This finding is consistent with the evidence reported by Hamermesh (1996) and Golden (2001). In addition, individuals who recently increased the time spent on working out-of-home per week are less likely to have a flexible work schedule than others, reflecting scheduling constraints. The frequency of train use has a positive association with the probability of having a flexible work schedule. This finding is in line with those of Schwanen et al. (2002) and Snellen (2002), who found that highly educated workers are more likely to travel by train.

With respect to ICT-related variables, regularly making work-related calls and sending work-related emails outside working hours had an impact on work schedule flexibility. The sign of this variable shows that individuals who make more work-related calls and send work-related emails outside working hours are more likely to have a flexible work schedule. The fact that they communicate outside working hours suggests that they have the opportunity and the freedom to organize their own working schedules. Also, the results in Table 2 indicate that the financial aspect of mobile phone use is also relevant to working 
arrangements. It appears that those financially reimbursed by their employers for mobile phone use are more likely to have working-schedule flexibility. This may reflect the fact that workers with a mobile phone paid for by the employer are likely to work extensively outside the office and consequently have more freedom to schedule their working day. However, having a combined phone and internet package reduces the work schedule flexibility. This finding was not expected, since we anticipated that these combined ICT services would result in more flexible work schedule.

Among the sociodemographic variables, age and household net income were observed to impact on work schedule flexibility. In contrast with our expectations, the presence of children at home did not affect work-schedule flexibility. We anticipated that the presence of children would be a main factor affecting work-schedule flexibility. In addition, we found that the probability of having work-schedule flexibility increases with age. This finding seems to be consistent with those of Yeraguntla and Bhat (2005) and Golden (2001), who found that younger employees are less likely to have a flexible work schedule. As expected, individuals with lower net household income are less likely to have a flexible work schedule than are individuals with higher incomes. These findings are also consistent with those of Yeraguntla and Bhat (2005). Further, the result shows that the association between gender and flexible work schedule was not statistically significant. We expected gender differences in work schedule flexibility. For example, women would have more flexible work schedule than men, because they face more space-time constraints and are more likely to schedule paid-labor activities around domestic commitments than men do (Kwan 2000).

The distribution of start and end times of work activities

Before discussing stochastic frontier models, it is worth paying attention to a sample of scatter plots. In Fig. 1, the empirical relationship between the start and end times of work activities at home and work places is presented. The scatter plots of out-of-home working (Fig. 1a) indicate that the start and end times of out-of-home working are more concentrated than those for working at home. Higher rates of out-of-home working activities are located during traditional business hours (9 a.m. to 6 p.m.). However, it can also be seen that a substantial proportion of respondents choose to work with a flexible working schedule. When compared with working out-of-home, the distribution of start and end times for in-home working (Fig. 1b) has more variation and is highly heterogeneous for both the start and end times. This finding may indicate that people working at home have more flexible schedules than do those working outof-home. Moreover, the distribution shows that an earlier start time is associated with an earlier end time for in-home work, indicating that if one starts work early then one ends early as well. Another important finding is that there is a strong positive relationship between the end time of working out-of-home and the start time of working after a commute (Fig. 1c; $r=.76, p<0.01$ ). Similarly, a later end time for before-commute working has a positive association with a later start time for working out-of-home (Fig. 1d). This finding suggests that before commute, out-of-home, and after-commute work tend to follow each other sequentially. As shown in Fig. 1e, no clear correlation exists between out-of-home start times and after-commute start times. There is a tendency, however, that if the before-commute starts later, so does out-ofhome working (Fig. 1f). 

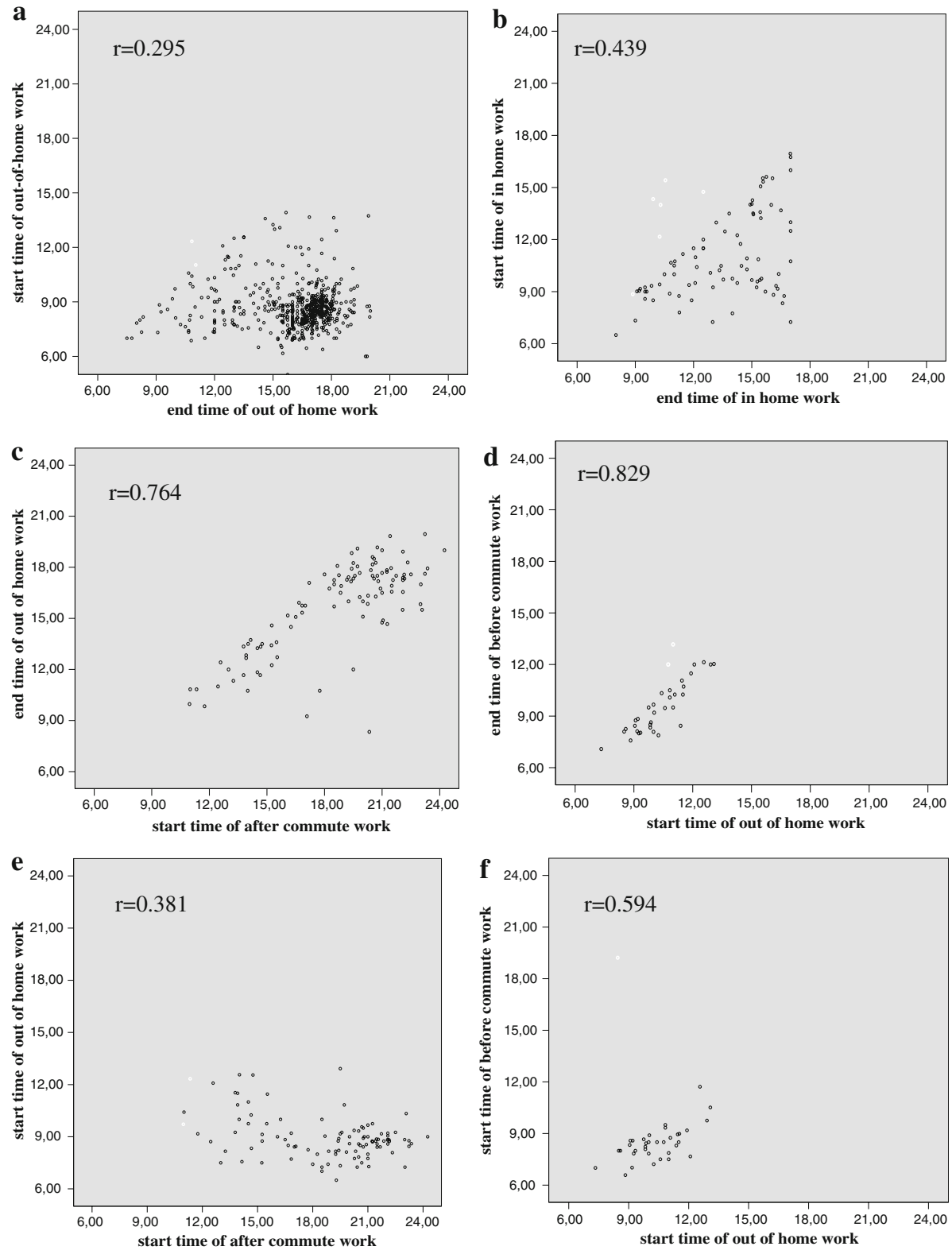

Fig. 1 Scatter plots of start and end time of work activities

\section{Estimation results of stochastic frontier models}

In this section, we discuss the results of the models for the earliest possible start time and the latest possible end time. The dependent variables of the models are expressed in hours.

The results of EPST models. The comparisons of the observed start time of work and the earliest possible start time for in-home and out-of-home working are displayed in Fig. 2. 




Fig. 2 Distribution of observed start time of work and EPST

Table 3 Stochastic frontier models for the earliest possible start time

\begin{tabular}{|c|c|c|c|c|c|c|}
\hline \multirow[t]{2}{*}{ Variables } & \multicolumn{2}{|c|}{ Out-of-home } & \multicolumn{2}{|l|}{ In-home } & \multicolumn{2}{|c|}{ Before commute } \\
\hline & Coef & $t$ & Coef & $t$ & Coef & $t$ \\
\hline Constant & 7.46 & 30.6 & 9.63 & 14.4 & 6.83 & 32.83 \\
\hline Weekly working hours & & & -0.03 & -2.92 & & \\
\hline Duration of private calls (min) & 0.002 & 1.83 & 0.018 & 3.01 & & \\
\hline Internet experience (in years) & 0.03 & 2.86 & -0.04 & -0.92 & & \\
\hline Buy laptop enable working anywhere, anytime & 0.38 & 3.17 & & & 0.99 & 2.89 \\
\hline Male & -0.22 & -2.75 & -1.05 & -2.21 & & \\
\hline Age & 0.08 & 2.02 & & & & \\
\hline Household type: live with partner and child & & & -1.06 & -2.27 & & \\
\hline Urban degree: $<1,000$ address $/ \mathrm{km}^{2}$ & 0.27 & 2.98 & & & & \\
\hline Household net income: $<2,000$ euro per month & & & & & 2.57 & 7.18 \\
\hline$L(\mathrm{C})$ & -803 & & -216.7 & & -88.67 & \\
\hline$L()$ & -833.7 & & -228.7 & & -74.06 & \\
\hline$E(u)$ & 0.88 & & 2.63 & & 1.32 & \\
\hline $\operatorname{var}(u)$ & 0.77 & & 6.92 & & 3.06 & \\
\hline $\operatorname{var}(v)$ & 0.33 & & 1.06 & & 1.75 & \\
\hline$N$ & 562 & & 110 & & 49 & \\
\hline
\end{tabular}

Note: Positive coefficient indicates a later EPST

With respect to observed start times for work, at least $40 \%$ of the sample starts out-ofhome work in the half-hour period between 8.30 a.m. and 9.00 a.m. The distribution of the start time of in-home work also shows a peak around $10.00 \mathrm{am}$. The estimation results of the EPST models are presented in Table 3. It should be noted that all the 28 independent variables were tested: for example, the possession of a PDA and laptop, the frequency of land-line phone calls, the possession of a satellite navigation device, the number of cars per household, commute duration and education level (Table 1).

We have only included statistically significant variables in the results table. The results suggest that the start time for in-home work is later than for the out-of-home work activity. 
A possible explanation is that people working from home are more likely to engage in inhome or out-of-home household activities, such as taking children to school, and so their work may start later in the morning. A similar result was also found by Pendyala et al. (2004), who report that working at home has a later start time than working out-of-home. Table 3 indicates that expected values of differences between the observed start time and EPST for out-of-home working and in-home working were 0.88 and $2.63 \mathrm{~h}$ respectively. This result suggests that the start time for in-home working is more flexible than that for out-of-home working.

With respect to out-of-home work activities, Table 3 shows that a longer duration of private calls is associated with a later start time, indicating that people who frequently make private calls are less likely to start work early. The coefficient estimates of internet experience suggest that people with longer internet experience are more likely to have a later EPST. Individuals who bought a laptop with the intention of working anywhere and anytime have a slightly later EPST, suggesting a more flexible start time for work. In line with other studies, men tend to have an earlier EPST than women do, most probably through their lack of household obligations. As shown in Table 3, seniors are more likely to start work later than younger individuals. It also appears that people who live in less urbanized areas start work later than others.

As far as the EPST model for in-home working is concerned, the results suggest that individuals who work more hours are more likely to have an earlier start time, as one would expect. The coefficient estimate of the duration of private calls again suggests that people who frequently make private calls are less likely to start work at home early. This suggests that private calls push the location of EPST later. The estimation results further suggest that longer internet experience is associated with earlier start times for in-home working. This effect contrasts with that for out-of-home working. As expected, men tend to have an earlier EPST than women do. It was also found that those individuals who live with a partner and have children are more likely to have an earlier start time for in-home working. In line with our expectations, the average difference between the observed start time and the EPST for in-home working is greater than for out-of-home and before commute working, indicating more variation in in-home work start times. This result reinforces the finding that the schedule for in-home working is more flexible than that for out-of-home working.

As mentioned above, the proportion of people engaging in work activity before their commute is fairly small. We therefore estimated the before-commute model with only two variables. Table 3 suggests that people who have a laptop that enables them to work anywhere and anytime tend to have a later EPST for before-commute working. Low net household income is associated with a slightly later EPST for work. The value of $E[u]$ was $1.32 \mathrm{~h}$, indicating that the observed start time for the before commute is, on average $1.32 \mathrm{~h}$ after the EPST. Compared with in-home working, a start time for before-commute working has less variation. This is logical, since the out-of-home work activity that necessarily follows the in-home work episode imposes additional constraints on this activity.

The results of LPET models. Table 4 presents the results of the LPET models for out-ofhome, in-home, and after-commute working. The models were found to provide a substantially poorer overall goodness-of-fit compared with the EPST models. This is probably the result of the greater variation in the end times of work. Looking at the sample distributions (Fig. 3), the distributions of end times for out-of-home work shows a broad peak in the period between 4 p.m. and 6 p.m. However, the distributions of the observed end times for in-home working and after-commute working have more variation, indicating more variation in end times. The LPET models are formulated by a production frontier. 
Table 4 Stochastic frontier models for the latest possible end time

\begin{tabular}{|c|c|c|c|c|c|c|}
\hline \multirow[t]{2}{*}{ Variable } & \multicolumn{2}{|c|}{ Out-of-home } & \multicolumn{2}{|l|}{ In-home } & \multicolumn{2}{|c|}{ After commute } \\
\hline & Coef & $t$ & Coef & $t$ & Coef & $t$ \\
\hline Constant & 17.61 & 82.4 & 18.1 & 71.2 & 22.98 & 40.39 \\
\hline Flexible work schedule & 0.30 & 2.65 & & & & \\
\hline Working from home & -0.25 & -1.91 & & & & \\
\hline High professional & 0.27 & 2.14 & & & 1.21 & 2.02 \\
\hline Manager & & & & & 2.73 & 3.65 \\
\hline Frequency of train use & & & & & 0.003 & 1.97 \\
\hline Commute distance $(\mathrm{km})$ & & & -0.017 & -2.41 & & \\
\hline $\begin{array}{l}\text { Frequency of mobile phone calls: } \\
\text { more than } 5 \text { calls a day }\end{array}$ & 0.32 & 2.13 & & & -1.81 & -3.58 \\
\hline Internet experience (in years) & 0.03 & 1.85 & & & & \\
\hline $\begin{array}{l}\text { Household type: live with partner } \\
\text { and children }\end{array}$ & & & 0.57 & 2.15 & & \\
\hline Partner's working hour & & & & & -0.03 & -1.99 \\
\hline$L(C)$ & $-1,050$ & & -290.9 & & -242.2 & \\
\hline$L()$ & $-1,071.4$ & & -286.6 & & -258.9 & \\
\hline $\operatorname{var}(v)$ & 0.53 & & 0.19 & & 1.13 & \\
\hline$E(u)$ & 3.44 & & 3.78 & & 4.06 & \\
\hline $\operatorname{var}(u)$ & 11.8 & & 14.26 & & 16.48 & \\
\hline$N$ & 542 & & 110 & & 108 & \\
\hline
\end{tabular}

Note: Positive coefficient indicates a later LPET

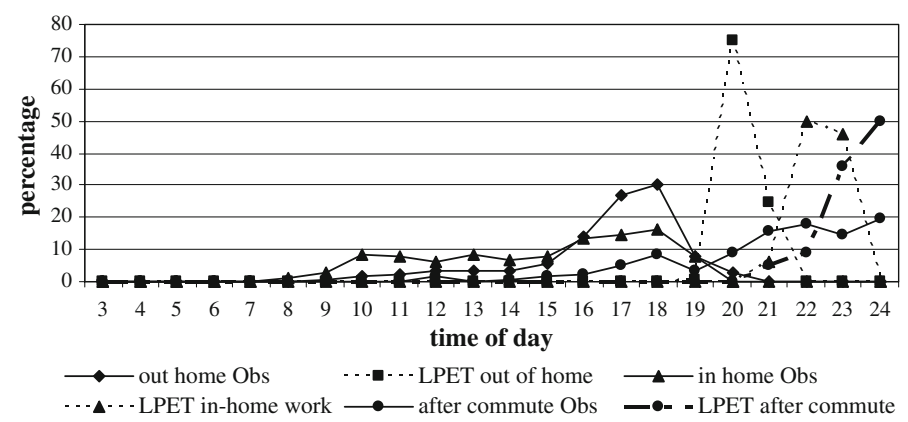

Fig. 3 Distribution of observed end time of work and LPET

With respect to out-of-home working, Table 4 indicates that individuals who have a flexible working schedule tend to end work later. This result suggests that these people probably avoid the evening commute congestion by shifting their working time. In addition, we find that out-of-home workers who occasionally work from home have an earlier end time, probably because they can also finish work activities from home. Consistent with our expectations, it was found that high-level professionals (scientific, technical, healthcare, and so forth) finish their work later than others. Among the ICT variables, the frequency of mobile phone calls and internet experience were associated with the end time for working. The results indicate that people who frequently use mobile phones tend to 
have a later LPST. In addition, those who have a greater number of years internet experience are more likely to have a later LPST. This finding is presumably because greater internet experience was associated with later start times in the EPST model for out-ofhome working. The reader will recall that people who start work later also tend to end later (Fig. 1). Surprisingly, the results indicate that the association between socio-demographic characteristics and LPET was not statistically significant. This finding might suggest that employment and ICT characteristics are associated with the end time for out-of-home working more strongly than sociodemographic variables. The difference between the observed end time for out-of-home working and LPET was $3.44 \mathrm{~h}$, indicating more variation in the end times than start times.

The result of the LPET model for in-home working shows that two variables were associated with end time of work. The influence of the first variable, commute distance, shows that the LPET is pushed earlier in time as the commute distance increases. This suggests that people used to a longer commute with an earlier departure time are more likely to end work at home early. The effect of the second variable suggests that people who live with a partner and have children tend to have later end times for in-home working. This may reflect household obligations and the responsibilities of couples. The estimation results indicate that ICT characteristics do not have a significant association with the LPET for in-home working. Employment and sociodemographic characteristics seem to be more strongly associated with in-home working end times. The results so far show that the difference between the observed end time and LPET for in-home working is greater than for out-of-home working. This finding suggests that in-home working schedules are more flexible than out-of-home working schedules.

With respect to the after-commute working model, we found that individuals who work in professional and managerial occupations are more likely to have a later LPET, suggesting more independence in the scheduling of work activities, but also a higher work load. Table 4 shows further that the frequency of train use is associated with a later LPET, presumably owing to the longer commute time associated with public transport. Another interesting finding is that the end time of after-commute work is shifted earlier as the partner's working hours increase. This finding may be attributed to the greater level of household obligations of couples. The result shows that the mean observed end time for after-commute working is about $4.06 \mathrm{~h}$ prior to the LPET with a greater variance compared with the end time for in-home and out-of-home working.

\section{Conclusion}

This study had a double goal: to determine the factors associated with adopting flexible work schedules; and to establish how and to what extent the timing of work is influenced by ICTs, employment and sociodemographic characteristics. We used a two-day activitytravel-communication diary survey collected among 662 individuals residing in the Utrecht-Amersfoort-Hilversum area in the central part of the Netherlands.

The results of binary logistic regression suggest that employment characteristics and ICT usage seem to be more important for the decision to have flexible work schedule than sociodemographic characteristics. For example, among the occupations, high-level professionals (scientific, technical, healthcare, ICT professionals, and so forth) are more likely to have a flexible work schedule. We also found mostly positive relationships between ICT ownership and use and work-schedule flexibility. 
Stochastic frontier models were applied to estimate the earliest possible start and latest possible end times for working. In order to gain more insight into the timing of work activities, we distinguished four categories of working arrangement: (1) in-home, (2) outof-home, (3) before commute; (4) after commute working. The analysis has shown that the majority of the respondents work out-of-home during the traditional business hours. However, we also found that a substantial proportion of respondents tend to opt for work with a flexible working schedule. The results show that, compared with working out-ofhome, the timing of the in-home working was spread out more across time, and was highly heterogeneous both for the start and end times.

Concerning the effects of work, ICT, and personal attributes on the start and end times of work activities, we found that ICT usage and personal-household characteristics were associated with the start times of work activities, while work-related and ICT variables were especially important for the end times. As expected, men start work earlier than women. Moreover, it appears that seniors and people who live in less urbanized areas tend to start work later than others. Individuals who work in professional and managerial occupations are more likely to have a later end time for working.

The empirical results from this study yield important insights and information for policy makers and transport planners. For instance, for policy makers this is highly relevant for the successful implementation of road pricing schemes. Similarly, more flexibility in work schedule has furthermore been predicted to impact on congestion and traffic patterns, therefore the finding of this study give insights which people are willing to shift timing of their commute trip.

There are several avenues remain for further research. First, the impact of flexible work schedule on an individual's travel behaviour should be explored in future studies. In the current study, the analysis of before-commute and after-commute working is limited, because of the limited sample size of the dataset. For example, to study the reduction of period traffic congestion through teleworking, it is important to increase the sample size and use travel indicators such as the departure time of a commute trip in the analysis. Second, the data we have used in the current study are cross sectional, so the day-to-day variation in start and end times cannot be detected. In order to address this issue, the timescale of the data could be expanded to week long data (Viswanathan and Goulias 2001).

Open Access This article is distributed under the terms of the Creative Commons Attribution Noncommercial License which permits any noncommercial use, distribution, and reproduction in any medium, provided the original author(s) and source are credited.

\section{References}

Aigner, D., Lovell, C.A.K., Schmidt, P.: Formulation and estimation of stochastic frontier production function models. J. Econom. 6, 21-37 (1977)

Bhat, C.R., Singh, S.K.: A comprehensive daily activity-travel generation model system for workers. Transp. Res. A 34, 1-22 (2000)

Burns, L.D.: Transportation, Temporal, and Spatial Components of Accessibility. D.C. Heath, Lexington (1979)

Chesley, N.: Blurring boundaries? Linking technology use, spillover, individual distress, and family satisfaction. J. Marriage Fam. 67(5), 1237-1248 (2005)

Couclelis, H.: Housing and the new geography of accessibility in the information age. Open House Int. 28(4), 7-13 (2003)

Couclelis, H.: The construction of the digital city. Environ. Plann. B Plann. Des. 31, 5-19 (2004) 
Cullen, I., Godson, V.: Urban networks: the structure of activity patterns. Prog. Plann. 4, 1-96 (1975)

Damm, D.: Theory and empirical results: a comparison of recent activity-based research. In: Carpenter, S., Jones, P.M. (eds.) Recent Advances in Travel Demand Analysis, pp. 3-33. Gower, Aldershot (1983)

Fast, J., Frederick, J.A.: Working arrangements and time stress. Can. Soc. Trends 43, 14-19 (1996)

Golden, L.: Flexible work schedule: what are we trading off to get them? Mon. Labor Rev. 124(3), 50-67 (2001). (Bureau of Labor Statistics, U.S. Department of Labor)

Graaff, T.D., Rietveld, P.: Substitution Between working at home and out-of-ome: the role of ICT and commuting costs. Transp. Res. Part A 41, 42-160 (2007)

Hägerstrand, T.: What about people in regional science? Pap. Reg. Sci. Assoc. 24, 7-21 (1970)

Hamermesh, D.: Workdays, Workhours and Work Schedules. W. E. Upjohn Institute for Employment Research, Kalamazoo (1996)

Handy, S.L., Mokhtarian, P.L.: The future of telecommuting. Futures 28, 227-240 (1996)

Hinze, S.W.: Inside medical marriages: the effect of gender on income. Work Occup. 27, 464-499 (2000)

Hubers, C., Dijst, M., Schwanen, T.: ICTs, coping strategies and gender differences in the temporal and spatial fragmentation of paid labor. In: 4th International Specialist Meeting on ICT, Everyday Life and Urban Change, Bristol, UK (2008)

Jones, P.M., Dix, M.C., Clarke, M.I., Heggie, I.G.: Understanding Travel Behaviour. Gower, Aldershot (1983)

Kakihara, M.: Emerging work practices of ICT-enabled mobile professionals. Unpublished Doctoral Dissertation, London School of Economics and Political Science University of London. Retrieved Feb 14: http://www.kakihara.org (2005)

Kakihara, M., Sørensen, C.: Mobile urban professionals in Tokyo: tales of locational, interactional and operational mobility. J Policy Regul. Strategy Telecomm. Inf. Media 6(3), 180-187 (2004)

Kitamura, R.: Sequential, history-dependent approach to trip-chaining behavior. Transp. Res. Rec. 944, 13-22 (1983)

Kitamura, R., Yamamoto, T., Kishizawa, K., Pendyala, R.M.: Stochastic frontier models of prism vertices. Transportation research record 1718. J. Transp. Res. Board 18-26 (2000) (National Research Council, Washington, DC)

Koenig, B., Henderson, D., Mokhtarian, P.: The travel and emissions impacts of telecommuting for the State of California telecommuting pilot project. Transp. Res. C 4(1), 13-32 (1996)

Kwan, M.P.: Gender differences in space-time constraints. Area 32(2), 145-156 (2000)

Kwan, M.P.: Time, information technologies and the geographies of everyday life. Urban Geogr. 23(5), 471-482 (2002)

Lund, J., Mokhtarian, P.L.: Telecommuting and residential location: theory and implications for commute travel in the monocentric metropolis. Transp. Res. Rec. 1463, 10-14 (1994)

Lyons, G., Haddad, H.: An exploration of demographic, work, home and commute aspects of part-day and whole-day homeworking. In: 4th International Specialist Meeting on ICT, Everyday Life and Urban Change, Bristol, UK (2008)

Mannering, J.S., Mokhtarian, P.L.: Modeling the choice of telecommuting frequency in California: an exploratory analysis. Technol. Forecast. Soc. Change 49(1), 49-73 (1995)

Mokhtarian, P.L., Salomon, L.: Modeling the desire to telecommute: the importance of attitudinal factors in behavioral models. Transp. Res. A 31(1), 35-50 (1997)

Mokhtarian, P.L.: A synthetic approach to estimating the impacts of telecommuting on travel. Urban Stud. 35(2), 215-241 (1998)

Mokhtarian, P.L., Salomon, L., Choo, S.: Measuring the measurable: why can't we agree on the number of telecommuters in the U.S.? Qual. Quant. 39, 423-452 (2005)

Nehra, R.S., Banerjee, A., Pendyala, R.M., Dhingra, S.L.: Analysis of personal time-space prism vertex locations. Transportation research record 1898. J. Transp. Res. Board 19-27 (2004) (National Research Council, Washington, DC)

Pendyala, R.M., Goulias, K.G., Kitamura, R.: Impact of telecommuting on spatial and temporal patterns of household travel. Transportation 18(4), 383-409 (1991)

Pendyala, R.M., Yamamoto, T., Kitamura, R.: On the formation of time-space prisms to model constraints on personal activity-travel engagement. Transportation 29, 73-94 (2004)

Presser, H.B.: Race-ethnic and gender differences in nonstandard work shifts. Work Occup. 30, 412-439 (2003)

Sall, E.A., Bhat, C.R., Reckinger, J.: An analysis of weekend work activity patterns in the San Francisco Bay Area. In: Transportation Research Board (TRB) Annual Meeting, Washington, DC (2005)

Schwanen, T., Dijst, M.: Time windows in workers' activity patterns: empirical evidence from the Netherlands. Transportation 30(3), 261-283 (2003) 
Schwanen, T., Kwan, M.P.: The internet, mobile phone and space-time constraints. Geoforum 39, 13621377 (2008)

Schwanen, T., Dijst, M., Dieleman, F.M.: A microlevel analysis of residential context and travel time. Environ. Plann. A 34, 1487-1507 (2002)

Snellen, D.: Urban form and activity-travel patterns, an activity-based approach to travel in a spatial context. Unpublished Doctoral Dissertation, Eindhoven University of Technology (2002)

Spitze, G.: Women's employment and family relations: a review. J. Marriage Fam. 50, 595-618 (1988)

Sullivan, S., Lussier, R.: Flexible work arrangements as a management tool: part 1. Supervision 56(8), 14-17 (1995)

Swanberg, J., Pitt-Catsouphes, M., Drescher-Burke, K.: Organizational justice: access to flexible work arrangements. J. Fam. Issue 26, 866-895 (2005)

Tausig, M., Fenwisk, R.: Unbinding time: alternate work schedules and work-life balance. J. Fam. Econ. Issue 22(2), 101-119 (2004)

Tillema, T., Dijst, M., Schwanen, T.: Electronic and face-to-face communication in maintaining social relationship. In: Transportation Research Board (TRB) Annual Meeting, Washington, DC (2008)

Toffler, A.: The Third Wave. Collins, New York (1980)

Valenduc, G., Vendramin, P.: ICT, flexible working and quality of life. In: European Conference, Unity and Diversity, Workshop 3: Social and Cultural Changes: The Impact on Well-being Bruges (2001)

Vana, P., Bhat, C.R., Mokhtarian, P.: On modelling the choice of work-hour arrangement, location and frequency of telecommuting. In: 87th Annual Meeting of the Transport Research Board (TRB), Washington, DC (2008)

Venkatesh, A., Vitalari, N.P.: An emerging distributed work arrangements: an investigation of computerbased supple-mental work at home. Manage. Sci. 38(12), 1687-1706 (1992)

Vilhelmson, B., Thulin, E.: Is Regular work at fixed places fading away? The development of ICT-based and travel-based modes of work in Sweden. Environ. Plann. A 33, 1015-1029 (2001)

Viswanathan, K., Goulias, K.G.: Travel Behavior Implications of Information and Communications Technology in Puget Sound Region, pp 157-165. Transportation Research Record, Transportation Research Board, No. 1752, TRB, National Research Council, Washington, DC (2001)

Yeraguntla, A., Bhat, C.R.: A classification taxonomy and empirical analysis of work arrangements. Transportation Research Record Board no. 1926. J. Transp. Res. Board 233-241 (2005) (National Research Council, Washington, DC)

\section{Author Biographies}

Bayarma Alexander is a post-doc researcher at the Urban and regional research centre Utrecht (URU) of the Faculty of GeoSciences, Utrecht University. She has obtained her PhD from the Department of Urban Management, Kyoto University, Japan. Her main research interest is activity-travel behaviour modelling, the variability of individual travel behaviour and the impact of ICT on human activity and travel patterns.

Martin Dijst is a professor in urban geography at the Faculty of GeoSciences, Utrecht University. His research activities are focused on transportation studies, land use planning and Information and Communication Technologies.

Dick Ettema is an associate professor at the Urban and regional research centre Utrecht (URU) of the Faculty of GeoSciences, Utrecht University. His research interests include activity-based modelling, the impact of land use on activity scheduling, household interactions and longer term adaptation processes. 